JELANI MANDARA Northwestern University

\author{
CAROLYN B. MuRRAY University of California, Riverside* \\ JAMES M. TELESFORD University of California, Berkeley**
}

FATIMA A. VARNER University of Michigan***

SCOTT B. RichmaN Northwestern University****

\title{
Observed Gender Differences in African American Mother-Child Relationships and Child Behavior
}

\begin{abstract}
African American mother-child dyads $(\mathrm{N}=99)$ were observed interacting on a collaborative puzzle exercise. Raters blind to the purpose of the study rated the dyads on several mother and child behaviors. Mothers of daughters were rated as more empathetic, encouraging, warm, and accepting and less negative than mothers of sons. Male children were more challenging and less happy, relaxed, and engaged. Mediation analyses found that the differences in mother-child relationships explained the gender differences in child behavior. These patterns
\end{abstract}

Program of Human Development and Social Policy, Northwestern University, 2120 Campus Drive Evanston, IL60208 (j-mandara@northwestern.edu).

*Department of Psychology, University of California, Riverside, 900 University Ave., Riverside, CA 92521.

**Psychology Department, University of California, Berkeley, 3210 Tolman Hall, Berkeley, CA 94720-1650.

***Center for the Study of Black Youth in Context, University of Michigan School of Education, 610 E. University Ave., Rm. 1323, Ann Arbor, MI 48109.

****Human Development and Social Policy, Northwestern University, 2120 Campus Drive, Evanston, IL 60208.

Key Words: African Americans, gender differences, observational studies, parent-child relationships. were consistent across different child age groups and after controlling for family socioeconomic status. It was concluded that many of the gender disparities may be reduced with empirically informed and culturally sensitive parent training interventions that teach parents the necessity of being warm and loving as well as encouraging both male and female children to excel.

Boys are much more likely than girls to have behavioral problems at school and engage in delinquent and other risky behaviors (Chun \& Mobley, 2010; Miller, Malone, \& Dodge, 2010). Boys are also less academically motivated and are much more likely to be suspended than girls (Sirin \& Rogers-Sirin, 2005; Skiba, Michael, Nardo, \& Peterson, 2002). Several studies even found that mothers and teachers rate boys as less well behaved than girls (Winsler \& Wallace, 2002). Although these gender differences in behavior persist for all major ethnic groups, they appear to be especially large for African Americans (Williams et al., 2007). Thus, African American males are lagging behind African American females across a wide range of social and behavioral domains, and the differences are larger than they are among other ethnic groups. 
Several researchers have recently begun to explore the possibility that boys in general, and African American boys in particular, are more likely to misbehave because girls are simply parented better overall (Mandara, Varner, \& Richman, 2010). Very few studies, however, have examined this possibility among African Americans. Of the few that have been done so, most are small qualitative studies (Hill, 2002; Hill \& Zimmerman, 1995), based primarily on self-report surveys (Mandara et al., 2010), or focused on primarily poor mothers of very young children (Tamis-Lemonda, Briggs, McClowry, \& Snow, 2009). The purpose of the current study was to add to this literature by examining the degree to which observers rate the mother-child relationship and child behavior differently for African American boys and girls. A further purpose was to assess the degree to which differences in the mother-child relationship accounts for observed gender differences in child behavior.

\section{GENDER DIFFERENCES IN AFRICAN AMERICAN MOTHER-CHILD RELATIONS}

The idea that parents have different relationships with each of their children has been fairly well documented (Brody, Stoneman, \& McCoy, 1992; Shanahan, McHale, Crouter, \& Osgood, 2008). The underlying premise of the early studies was that because shared genetic and environmental experiences could not explain the often large sibling differences in behavior and mental health, siblings must have many unique environmental experiences that influence their development (Dunn, Stocker, \& Plomin, 1990). Several studies confirmed these ideas and found that mothers tend to have warmer and closer relationships with their daughters than they have with their sons (Shanahan, McHale, Crouter, \& Osgood, 2007; Tucker, McHale, \& Crouter, 2003). Girls are also monitored more and given many more household chores than boys (McHale, Updergraff, Jackson-Newsom, Tucker, \& Crouter, 2000; Pettit, Laird, Dodge, Bates, \& Criss, 2001), but boys tend to receive more and harsher punishments (Lytton \& Romney, 1991; McKee et al., 2007). Nevertheless, these studies have been almost exclusively done with European American families, and there are several reasons why these results may not be the same among African American families. For one, some researchers found that, compared to
European American families, African American families tend to be more egalitarian in their division of parental labor and assignment of household chores (Glauber, 2008; Gupta, 2006; Harris, 1996; B. Landry, 2000).

Only a few studies have directly examined the degree to which African American mothers have different relationships with their sons and daughters. In survey studies, most did not find differences in the maternal warmth received by male and female African American youth (Bean, Barber, \& Crane, 2006; Mandara \& Pikes, 2008; Mandara et al., 2010). Gender differences have, however, been found among dimensions other than warmth. In one of the first studies to assess differential socialization among African Americans, Hill and Zimmerman (1995) used qualitative methods with a small group of lowincome African American mothers of children with sickle cell anemia. They found that mothers of sons were more protective and more likely to consider their sons fragile than mothers of daughters. Hill (2002) also examined 35 African American mothers of various socioeconomic status (SES) backgrounds with qualitative interviews. Similar to the prior study, she concluded that African American mothers emphasized economic self-reliance and assertiveness for their daughters more than they did for their sons. Mothers also had higher educational expectations for their daughters. Moreover, in a sample of low-income, urban African American children who were exposed to high levels of community violence, mothers were more verbally aggressive with their sons than with their daughters (Sagrestano, McCormick, Paikoff, \& Holmbeck, 1999).

More recent studies have also examined the degree to which differential socialization accounted for differences in boys' and girls' behavior and achievement. In one observational study, poor African American mothers of first grade boys were found to be more controlling and less sensitive than African American mothers of girls during an interactive task (Tamis-Lemonda et al., 2009). Furthermore, maternal sensitivity and control partially mediated boys' lower responsiveness and task involvement. Another recent and larger study sampled 1,500 single-parent African American adolescents from the National Longitudinal Survey of Youth and also found that boys and girls reported receiving significantly different parental treatment (Mandara et al., 2010). 
The girls reported significantly more household chores and greater monitoring and decisionmaking freedom compared to boys. The homes of girls were also more cognitively stimulating than the homes of boys. Most importantly, parenting differences accounted for most of the achievement disparities, and a significant number of the mother reported differences in the behaviors of girls and boys.

\section{The CURRENT Study}

Overall, then, the few prior studies suggest that male and female African American children and adolescents are socialized differently in a number of areas, and these differences in socialization may result in behavioral differences. There are, however, a few significant limitations of prior studies that may greatly influence the validity of these results. For one, most of the prior studies used primarily low-income, single-mother and/or exclusively urban families. Second, most prior studies relied solely on self-report data. Although the vast majority of parenting research is based on self-report surveys, and the value of such methods is undeniable (Morsbach \& Prinz, 2006), parental or child self-reports are often limited because they rarely address parenting in specific contexts. They may also be biased toward either preserving a parent's image or retrospectively explaining current child behavior. Even when respondents are trying to be as honest as possible, they are often unaware of their own behavior (Morsbach \& Prinz, 2006). Furthermore, some studies suggest that coded observations of parent-child interactions are stronger predictors of specific outcomes than self-report surveys (Patterson \& Forgatch, 1995). To address some of these limitations, in the current study, observations of economically diverse African American mothers and one of their children engaging in a joint puzzle-solving activity were coded for a variety of parent and child behaviors. Unlike prior studies, we also assessed youth from different age groups.

Our primary hypotheses are based on the few prior survey and observational studies with African American families and the fundamental premise of most modern parenting theories that children's engagement, mood, and behaviors are primarily due to their socialization experiences (Mandara, 2008). This conceptual framework would therefore suggest that the gender differences in academic engagement and behavior observed in the larger society developed as a consequence of boys and girls receiving differential treatment from important socialization agents such as parents and teachers. In particular, parents' emotional support, displays of warmth, positive affect, and other responsiveness behaviors are strongly associated with child task engagement and positive mood (S. H. Landry, Smith, \& Swank, 2006; Tamis-Lemonda et al., 2009). Thus, in the current study, we expected that observers would rate the mothers of girls higher on measures related to emotional responsiveness compared to mothers of boys. For instance, we expected more smiling and laughing and generally more positive affect among mothers of girls. Given the findings of prior studies that suggest mothers of sons are more protective of them than mothers of daughters and the fact that boys tend to have significantly fewer chores than girls (Mandara et al., 2010), we also expected mothers of sons to complete more of the puzzle and dominate or control the situation more than mothers of daughters. We also expected significant gender differences in child behavior. Specifically, we expected the boys to be less engaged or motivated to participate in the puzzle task compared to girls. Finally, we expected the differential parent-child relationships to mediate the relationship between child gender and behavior.

\section{METHOD}

\section{Participants}

The participants included 99 African American mother-child dyads from various cities in southern California. Fifty-five of the children were female. The children were $7,10,13$, or 16 years of age. About $29 \%$ of the children were 7, 25\% were $10,25 \%$ were 13 , and $21 \%$ were 16 years of age. The mothers' ages ranged between 24 and $52(M=37)$. The median annual household income was approximately $\$ 27,500$. Roughly $25 \%$ of the mothers had annual family incomes of $\$ 15,000$ or less, and $27 \%$ had incomes above $\$ 40,000$ per year. The mothers had one to six children $(M=2.6, S D=1.04)$, but only one participated in the current study. The mothers also averaged approximately 13 years of education $(S D=1.26)$. These descriptive statistics are very representative of African American families in southern California at the time of data collection (U.S. Bureau of the Census, 1996). 


\section{Procedure}

In the first year of the larger study, African American children ages $6,9,12$, or 15 were recruited through four school districts in southern California. District officials mailed a request and permission form to their parents. Of the families who responded, about 50 children born in the United States were randomly selected within each gender and age group $(N=413)$. During the second wave of the study, 99 of the children and their mothers from the larger sample participated in videotaped interactions. The first 99 dyads were the first families who could be seen, based on researcher and parental scheduling constraints. This resulted in a roughly random selection of families. The 99 families were identical to the larger sample in income and the probability of having a male or female child in the study. Each mother received \$25 and each child $\$ 10$ for their participation.

The study was conducted at small offices away from the main university campus. Each dyad was told by the experimenter to work collaboratively for 10 minutes to assemble mosaic puzzle pieces into a design of their choosing. The experimenter then left the room. A camera recorded video and audio of the interaction. The experimenter returned after 10 minutes and thanked the families for their participation. They were then paid their honoraria in cash.

Two to four trained undergraduate raters, blind to the purpose of this study, then viewed each of the videotaped interactions independently and assessed the dyads on various mother and child behaviors. More specifically, the observers independently rated each dyad on 60 items. Mothers were coded on 39 parenting and emotional expression descriptors (e.g., warmth, acceptance, controlling, anger, encouragement), and children were coded on 21 behavioral descriptors (e.g., passive, engaged, happy, angry, relaxed). The coding instrument was adapted from the Black Family Process Q-sort (Peacock, Murray, Ozer \& Stokes, 1996), the Dyadic Parent-Child Interaction Coding System (Eyberg, McDiamid, Duke, \& Boggs, 2004), and the behavioral categories seen in other prominent observational coding systems for parent-child interactions (Aspland \& Gardner, 2003). Most of the items on the instrument used Likert-type scales ranging from $0=$ not at all descriptive to $4=$ completely descriptive. Fourteen of the 39 items concerned with the mother's parenting asked raters various questions such as, "How much of the puzzle does the mother complete herself? $(0=$ None to $4=$ All of it $)$ " or "How often does the mother ask for her child's opinion? $(0=$ Not at all to $4=$ All of the time $)$." Raters viewed the videotape as many times as they liked, at their own pace, but for a minimum of two viewings. As described in more detail below, the interrater reliabilities were strong for the mother (average $\alpha=.82$ ) and child (average $\alpha=.87$ ) behaviors. Thus, scores from the raters were averaged for each of the 60 items.

\section{Measures}

Family SES. Mothers reported their annual family income on 12 intervals ranging from $\$ 0-\$ 4,999$ to over $\$ 100,000$. To approximate actual income in dollars, each variable was coded by assigning values that correspond to the middle point of each interval. To determine the income per person, the annual household income was divided by the number of people in the home.

Maternal behavior. The rated maternal behavior items were first organized into the seven theoretical factors we adapted from other instruments. Principal components with varimax rotation, along with various combinations of factor analytic extraction and rotation methods, were used for each of the theoretical factors. The results were very similar across the different combinations and generally revealed that each theoretical factor represented one strong empirical factor with high internal consistency reliabilities after removing some items that did not load well on either factor. Although the seven factors were highly related and were later combined into two larger dimensions, we chose to initially keep the seven to illustrate the specific areas where gender differences were observed. The seven mothers' parenting factors were as follows: Maternal warmth was assessed with 10 items (e.g., warm, caring, warm voice, warm body language; $\alpha=.95)$; encouragement was assessed with 5 items (e.g., encouraging, engaging, interested; $\alpha=.89$ ); instructiveness with 2 items (instructive, instructiveness; $\alpha=.77$ ); empathy with 2 items (empathetic, sensitive; $\alpha=.85$ ); controlling with 7 items (e.g., controlling, demanding, passive; $\alpha=.93$ ); negativity with 4 items (e.g., cold, neglectful; $\alpha=.83$ ); and acceptance with 2 items (e.g., accepting, accepted; $\alpha=.83$ ). 
Child behavior. Principal components with varimax rotation, along with various combinations of factor analytic extraction and rotation methods, were used on the 21 coded child behavior items. Six items did not load well on either factor or with each other and were eliminated from further analysis. This resulted in four reliable and theoretically sound variables that explained $87 \%$ of the variance in the items. The degree to which the child was engaged was assessed with 7 items (e.g., assertive, talkative, not bored; $\alpha=.91$ ); relaxed was assessed with 2 items (relaxed, comfortable; $\alpha=.93$ ); happy with 3 items (happy, warm, loving; $\alpha=.97$ ); and challenging with 2 items (challenging, stubborn; $\alpha=.80$ ).

\section{Analysis Plan}

To test the main hypotheses, latent variable structural equation modeling (SEM) with maximum likelihood estimation using Amos 16.0 was employed. The composites of each factor were used as single indicators of their latent variable in the SEM analyses. To account for measurement error, the residuals were fixed to their error variances multiplied by their variances, and the paths from the indicators to their latent variables were set to the square root of the indicator's reliability (Stephenson \& Holbert, 2003). This helped simplify the model. SEM also allows for a test of the statistical significance of the direct (i.e., nonmediated) and indirect (i.e., mediated) effects of gender on the child behavior outcomes through parenting. Because the sample is somewhat small, bootstrap methods in AMOS 16.0 were used to estimate bias-corrected $p$ values, standard errors, and indirect effects. Bootstrapping methods will derive more accurate standard error estimates than Ordinary Least-Square Regression in smaller samples (Preacher \& Hayes, 2004). Overall model fit was assessed with the comparative fit index (CFI), the Tucker-Lewis Index (TLI), and the root-mean-square error of approximation (RMSEA) using standard criteria (Arbuckle, 2007).

The main analyses proceeded in five steps. First, the descriptive statistics were assessed. Then the effects of gender on the latent parenting and child behavior measures were assessed with SEM. In the next step, factor analyses were used to reduce the seven maternal parenting factors to simplify the model. Then, the full mediation model was fit to the data. The model suggests that the direct effects of gender on child behavior will be mediated by maternal parenting behaviors. In the final step, the multiple-group analysis was used to assess the moderating effects of age on the model. The multiple-group analysis assessed if the path diagram fit the data equally well for those 13 years and older and those under 13 .

\section{RESULTS}

The bivariate correlations between the study variables are presented in Table 1. As expected, the maternal parenting behaviors were strongly

Table 1. Correlations Among Study Variables

\begin{tabular}{|c|c|c|c|c|c|c|c|c|c|c|c|c|}
\hline Variable & 1. & 2. & 3. & 4. & 5. & 6. & 7. & 8. & 9. & 10. & 11. & 12. 13. \\
\hline 1. C. engaged & - & & & & & & & & & & & \\
\hline 2. C. relaxed & $.55^{* * *}$ & - & & & & & & & & & & \\
\hline 3. C. happy & $.79^{* * *}$ & $.61^{* * *}$ & - & & & & & & & & & \\
\hline 4. C. challenging & .12 & -.09 & -.10 & - & & & & & & & & \\
\hline 5. M. encourage & $.53^{* * *}$ & $.37^{* * *}$ & $.65^{* * *}$ & .10 & - & & & & & & & \\
\hline 6. M. warmth & $.77^{* * * *}$ & $.51^{* * *}$ & $.81^{* * *}$ & .01 & $.82^{* * *}$ & - & & & & & & \\
\hline 7. M. empathy & $.28^{* *}$ & $.28^{* *}$ & $.32^{* *}$ & .02 & $.22 *$ & $.44^{* * *}$ & - & & & & & \\
\hline 8. M. control & $-.29^{* *}$ & -.02 & -.04 & .12 & $.38^{* * *}$ & -.05 & $-.23^{*}$ & - & & & & \\
\hline 9. M. negativity & $-.59^{* * *}$ & $-.35^{* * *}$ & $-.68^{* * *}$ & -.02 & $-.76^{* * *}$ & $-.84^{* * *}$ & $-.37^{* * *}$ & -.10 & - & & & \\
\hline 10. M. acceptance & $.64^{* * *}$ & $.34^{* * *}$ & $.61^{* * *}$ & -.17 & $.34^{* * *}$ & $.72^{* * *}$ & $.44^{* * *}$ & $-.52^{* * *}$ & $-.58^{* * *}$ & - & & \\
\hline 11. M. instructive & .14 & .18 & $.26^{* *}$ & .06 & $.70^{* * *}$ & $.39^{* * *}$ & .11 & $.61^{* * *}$ & $-.41^{* * *}$ & -.07 & - & \\
\hline 12. Child age & $-.26^{* *}$ & -.13 & $-.31^{* *}$ & .04 & $-.35^{* * *}$ & $-.30^{* *}$ & -.19 & .03 & $.22^{*}$ & $-.20^{*}$ & $-.21^{*}$ & - \\
\hline 13. Family SES & .18 & .00 & .12 & .12 & .21 & .18 & -.06 & .06 & $-.26^{*}$ & .08 & .11 & .09 \\
\hline
\end{tabular}

Note: $N=99$ dyads. $\mathrm{C} .=$ child behaviors. $\mathrm{M} .=$ mother behaviors.

${ }^{*} p<.05,{ }^{* *} p<.01,{ }^{* * *} p<.001$. 
related to each other in predictable directions. Those mothers rated as warm were also more engaging, empathetic, and accepting. They were also much less negative. Most of the parenting measures were also moderately to very strongly correlated with each child behavior measure except for challenging, which also had little relationship to the other child behaviors. In general, the more emotionally responsive the mothers were rated during the interaction task, the happier, more engaged, and more relaxed their children were rated. Being controlling, however, was not strongly related to any child behavior except for engagement. The more controlling the mother, the less engaged the child tended to be. The higher the SES, the slightly more encouraging and less negative mothers tended to be. Family SES was not strongly related to the other variables, but the age of the child did have a significant relationship with many of the parenting variables. In general, the mothers of younger children were rated as more encouraging, warm, and less negative than mothers of older children.

To get a sense of the direct effects of gender on the maternal parenting and child behaviors, each latent variable was regressed on gender in an SEM model while controlling for child age and family SES. These results are presented in

Table 2. Parameter Estimates and Significance Levels for Gender Differences on the Study Variables

\begin{tabular}{lccc}
\hline \multirow{2}{*}{$\begin{array}{l}\text { Parenting and } \\
\text { Child Behaviors }\end{array}$} & \multicolumn{3}{c}{ Direct Effects of Gender } \\
\cline { 2 - 4 } & $b$ & $S E$ & $\beta$ \\
\hline C. engaged & $.27^{+}$ & .14 & .19 \\
C. relaxed & $.14^{*}$ & .08 & .19 \\
C. happy & $.49^{* *}$ & .18 & .26 \\
C. challenging & $.19^{*}$ & .10 & .19 \\
M. encouragement & $.25^{* *}$ & .10 & .19 \\
M. warmth & $.39^{* *}$ & .14 & .27 \\
M. empathy & $.25^{*}$ & .10 & .28 \\
M. control & .04 & .12 & .04 \\
M. negativity & $-.24^{*}$ & .12 & -.20 \\
M. acceptance & $.23^{*}$ & .13 & .20 \\
M. instructive & .16 & .25 & .08 \\
\hline
\end{tabular}

Note: $\mathrm{C}$. = child behaviors. M. = mother behaviors. Positive values indicate that females are higher. $N=99$ dyads. The standard errors and $p$ values are bias-corrected and were estimated with 500 bootstrap samples. Child age and family SES are controlled.

${ }^{+} p<.07,{ }^{*} p<.05,{ }^{* *} p<.01$.
Table 2 and show that girls were rated as being significantly more relaxed, happier, and slightly more engaged. The results also show that mothers of girls were rated as being significantly warmer, encouraging, accepting, and empathetic than mothers of sons. Mothers of girls were also less negative, but they did not differ much on the degree to which they were controlling or instructive.

Before testing the full mediation model, the seven maternal parenting variables were subjected to principal components analysis with varimax rotation. As is typically found in such data (Baumrind, 2005), the two primary dimensions of responsiveness and control were identified and accounted for $79 \%$ of the variance in parenting. Responsiveness $(\alpha=.86)$ included the measures of warmth, empathy, acceptance, encouragement, and lack of negativity. Control $(\alpha=.80)$ included the measures instructiveness and control. These factors were used to test the mediation models for each of the four child behavior outcomes.

In the next step, the full SEM with direct paths from gender to the latent responsiveness and control parenting factors and direct paths from parenting to each child outcome was estimated. The responsiveness and control residuals were allowed to correlate, and age and family SES were used as covariates in the analyses. The direct and indirect effects of the gender and parenting variables on the child outcomes are presented in Table 3. The models with child engaged, relaxed, and happiness fit the data very well (see Figures 1, 2, and 3), and explained $67 \%, 26 \%$, and $72 \%$ of the variance in each outcome, respectively. As seen in the earlier analyses, mothers of girls were rated as being much more responsive than mothers of boys, but they did not differ on controlling. Responsiveness was also a very strong predictor of child relaxed, happiness, and engagement during the task. The more responsive the mother was rated, the more relaxed, happy, and engaged the child was rated on average. Maternal control was only significantly related to child engagement. The more controlling the mother was rated, the less engaged the child was rated. Counter to these results, the model with child challenging as the outcome did not fit the data well, $\chi^{2}(1)=3.263$, $p=.07, \mathrm{CFI}=.90, \mathrm{RMSEA}=.15$, as none of the factors were significantly related to the outcome. 
Table 3. Parameter Estimates and Significance Levels for Direct and Indirect Effects of Gender and Parenting on Child Behaviors

\begin{tabular}{|c|c|c|c|}
\hline & $b$ & $S E$ & $\beta$ \\
\hline \multicolumn{4}{|l|}{ Direct effects on child behaviors } \\
\hline Responsiveness $\rightarrow$ C. engaged ${ }^{\mathrm{a}}$ & $.86^{* *}$ & .12 & .83 \\
\hline Control $\rightarrow$ C. engaged ${ }^{a}$ & $-.28^{* *}$ & .10 & -.28 \\
\hline Responsiveness $\rightarrow$ C. relaxed ${ }^{b}$ & $.57^{* *}$ & .12 & .56 \\
\hline Control $\rightarrow$ C. relaxed ${ }^{b}$ & -.01 & .11 & -.01 \\
\hline Responsiveness $\rightarrow$ C. happy ${ }^{\mathrm{c}}$ & $.86^{* *}$ & .10 & .86 \\
\hline Control $\rightarrow$ C. happy ${ }^{\mathrm{c}}$ & -.07 & .09 & -.07 \\
\hline Responsiveness $\rightarrow$ C. challenging ${ }^{\mathrm{d}}$ & -.04 & .13 & -.03 \\
\hline Control $\rightarrow$ C. challenging ${ }^{\mathrm{d}}$ & .11 & .14 & .10 \\
\hline \multicolumn{4}{|l|}{ Indirect effects of gender } \\
\hline Gender $\rightarrow$ C. engaged ${ }^{a}$ & $.43^{* *}$ & .18 & .21 \\
\hline Gender $\rightarrow$ C. relaxed ${ }^{b}$ & $.33^{* *}$ & .13 & .16 \\
\hline Gender $\rightarrow$ C. happy ${ }^{\mathrm{c}}$ & $.49^{* *}$ & .16 & .25 \\
\hline Gender $\rightarrow$ C. challenging ${ }^{\mathrm{d}}$ & .00 & .07 & .00 \\
\hline
\end{tabular}

Note: C. = child behaviors. $\mathrm{M}$. = mother behaviors. Positive values indicate that females are higher. $N=99$ dyads. The standard errors and $p$ values are bias corrected and were estimated with 500 bootstrap samples.

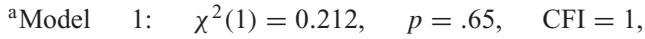
RMSEA $=0$.

${ }^{\mathrm{b}}$ Model $\quad 2: \quad \chi^{2}(1)=0.078, \quad p=.78, \quad \mathrm{CFI}=1$, RMSEA $=0$.

${ }^{\mathrm{c} M o d e l} \quad 3: \quad \chi^{2}(1)=0.097, \quad p=.76, \quad \mathrm{CFI}=1$, RMSEA $=0$.

${ }^{\mathrm{d}}$ Model $\quad 4: \quad \chi^{2}(1)=3.26, \quad p=.07, \quad \mathrm{CFI}=.90$, RMSEA $=.15$.

${ }^{* *} p<.01$.

Multiple-group analyses were then used on the three significant models to determine whether the models fit differently for those 13 years and older and those under 13. Results showed that the constrained and unconstrained models did not significantly differ for either outcome, meaning that the models fit equally well for each age group.

\section{DISCUSSION}

Several studies with European American samples show that parents differentially socialize their sons and daughters (Shanahan et al., 2007), but the research is still relatively new among African American families. This present study was designed to test the hypotheses that African American mothers have a different relationship with their sons and daughters, and these variations would explain gender differences in child engagement and behavior during a collaborative puzzle exercise. In particular, we predicted that mothers of daughters would be warmer and have less negative affect during the interaction than mothers of sons. We also predicted that mothers of sons would be more controlling of the situation than mothers of daughters. The results were largely in support of these hypotheses.

Mothers were rated significantly higher on emotional responsiveness measures such as warmth, empathy, and acceptance than they were rated on control and especially negative affect. This finding may be due partially to some mothers attempting to project a stereotypical image of an emotionally sensitive mother. It is more likely the case, however, that the pattern of results represents their actual dispositional parenting, considering the very strong relationships between mothers' parenting behaviors and child behaviors in the current study and that this same pattern was also found in a similar observational study with poor African American mothers of young children (Tamis-LeMonda et al., 2009). Overall, mothers who were rated as being warm, accepting, encouraging, empathetic, and generally expressing positive affect during the interaction had children who tended to be happier, engaged, and relaxed compared to the children whose mothers were lower on those responsiveness measures. Maternal control of the situation was not as strongly related to child behavior. The more controlling mothers were rated, however, the less engaged their child was also rated. These findings persisted even after controlling for family SES and child age. Furthermore, age did not moderate the gender differences in parent-child relationships or child behavior.

The nature of the observed parent-child relationship differed significantly on the basis of the child's gender. As hypothesized, and similar to the Tamis-LeMonda et al. (2009) observational study, the mothers of daughters were rated as being warmer, more encouraging, and more accepting of their daughters' participation and expressed more empathy or understanding than mothers of sons. Mothers of girls were also rated as being less likely to express negative affect toward their child than mothers of sons. A noteworthy aspect of this finding is that prior self-report survey studies with African American families have not found gender differences in the levels of maternal warmth reported (Mandara \& Pikes, 2008; Mandara et al., 2010). As 
Figure 1. Structural Equation Model of Maternal Parenting Mediating the Effects of Child Gender on CHILD ENGAGEMENT.

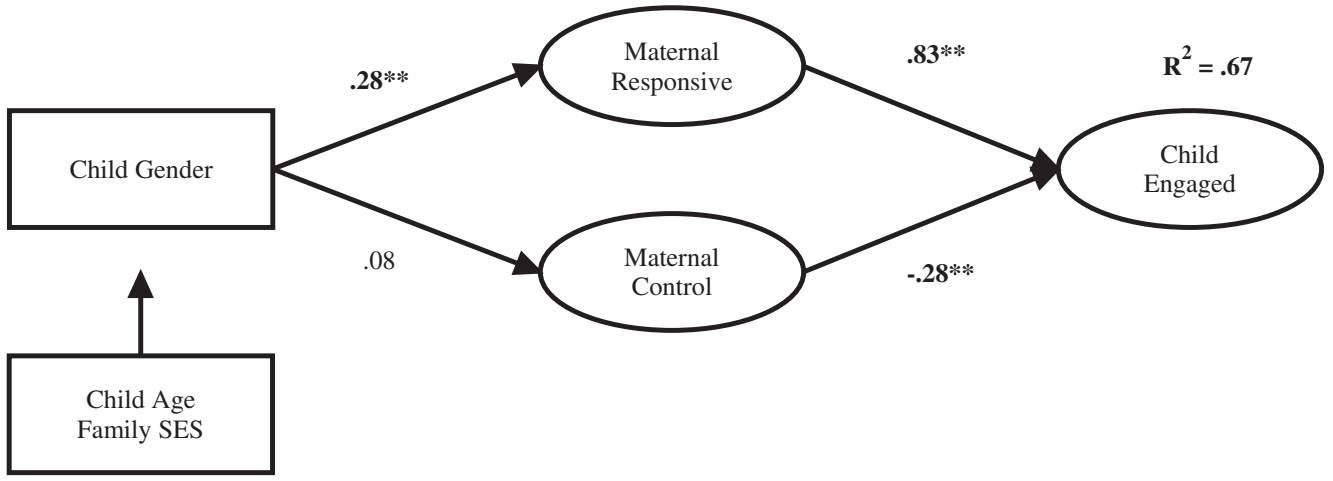

Note: Child age and family SES are covariates. The maternal parenting residuals were allowed to correlate but are not shown. For gender, boys were coded as 0 and girls as 1 . Values are standardized estimates. The $p$ values are bias corrected and were estimated with 500 bootstrap samples. $* * p<.01 \cdot \chi^{2}(1)=.212, p=.65, \mathrm{CFI}=1$, RMSEA $=0$.

Figure 2. Structural Equation Model of Maternal Parenting Mediating the EfFects of Child Gender on CHILD RELAXED.

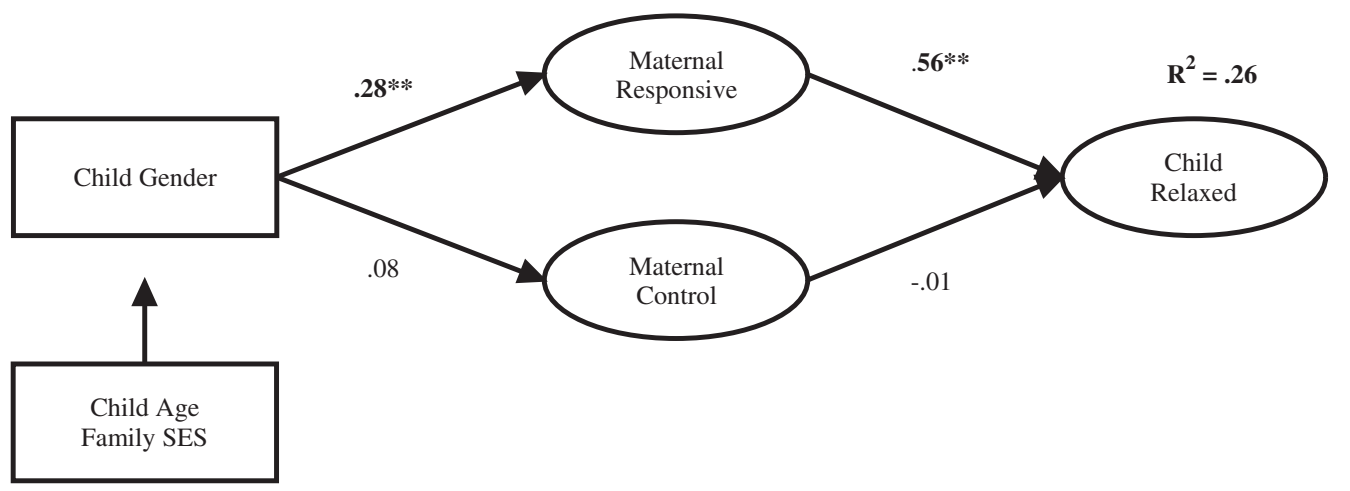

Note: Child age and family SES are covariates. The maternal parenting residuals were allowed to correlate but are not shown. For gender, boys were coded as 0 and girls as 1 . Values are standardized estimates. The $p$ values are bias corrected and were estimated with 500 bootstrap samples. ${ }^{*} p<.01 . \chi^{2}(1)=0.078, p=.78, \mathrm{CFI}=1$, RMSEA $=0$.

discussed earlier, the differences between the self-report studies and the observational studies could be that mothers are intimately aware of the camera during the interaction, and that could lead them to be more responsive. That argument is less valid, however, because the relative differences between males and females were rather robust. A more plausible explanation is that males and females perceive the same generally high levels of maternal warmth and overall responsiveness on self-report surveys, but observers are able to detect more nuanced differences. Some evidence suggests this may be the case (Sessa, Avenevoli, Steinberg, \& Morris, 2001). Future studies should further examine this possibility.

An interesting finding, which was counter to our expectations, was that mothers of sons were not rated as more controlling of the situation than mothers of daughters. We predicted that mothers of sons would be more controlling of the situation because they and their sons would be more used to the mothers doing basic chores for them. This is different from prior observational (Tamis-LeMonda et al., 2009) and survey (Mandara et al., 2010) studies 


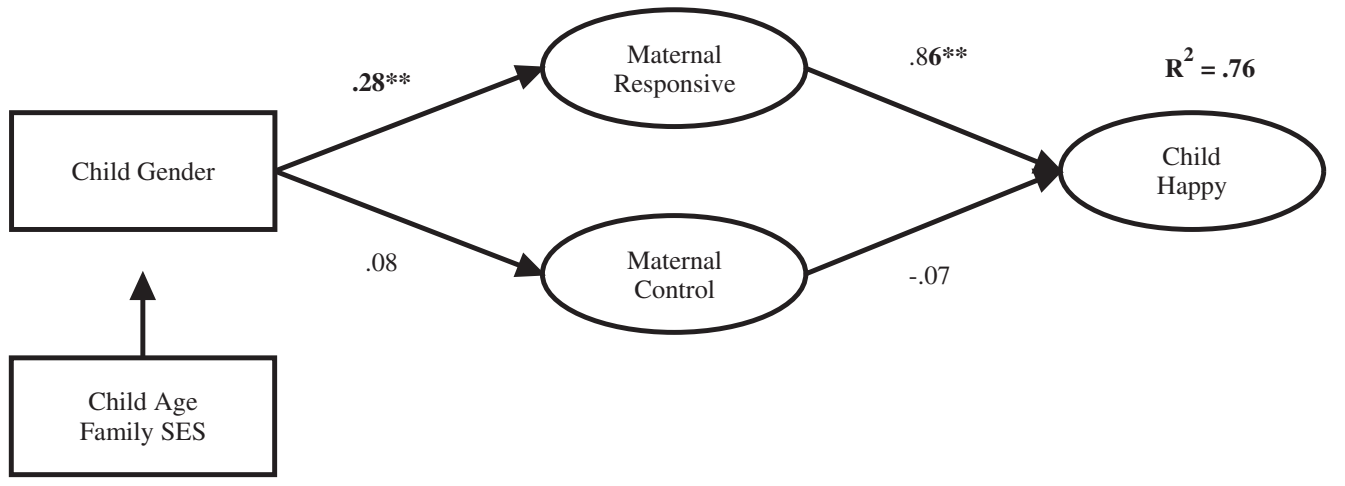

Note: Child age and family SES are covariates. The maternal parenting residuals were allowed to correlate but are not shown. For gender, boys were coded as 0 and girls as 1 . Values are standardized estimates. The $p$ values are bias corrected and were estimated with 500 bootstrap samples. $* * p<.01 . \chi^{2}(1)=0.097, p=.76, \mathrm{CFI}=1$, RMSEA $=0$.

with African American samples, which have found gender differences in overall maternal control. The differences between this study and prior studies are most likely due to issues of measurement. Most observational coding and self-report parenting instruments define parental control in terms of monitoring, criticism, and/or negativity. For instance, in the Tamis-LeMonda et al. study, mothers of sons were rated as more controlling than mothers of daughters. Their measure of maternal control, however, like most parent-child observational studies, was largely a measure of negative affect. In the current study, negative affect was also higher among mothers of sons than mothers of daughters, but it was considered lack of responsiveness and not control. In this study, maternal control represented the degree to which mothers' dominated or controlled the situation (e.g., doing most of the puzzle, not asking for the child's input). This is a very different conceptualization and likely explains the disparate findings.

Overall, the bulk of the evidence suggests that mothers are less warm and encouraging and express more negative affect with their sons than daughters during specific tasks. They also seem to offer autonomy in different ways. African American girls, like all girls, are monitored more than boys (Mandara et al., 2010; Smetana, 2000), and their interpersonal relationships and sexual behavior are scrutinized more diligently (Smetana \& Gaines, 1999). But, as with European American families (McKee et al.,
2007), African American parents are more likely to punish and use physical discipline with sons than daughters (Sagrestano et al., 1999). Given that mothers of girls in this study were more encouraging of their child's participation in the task than mothers of boys, but they did not necessarily do more of the task than mothers of boys, it seems like mothers are simply less demanding of their sons compared to their daughters. Mandara et al. came to a similar conclusion and argued that mothers are not necessarily more permissive with their sons, but they are less demanding.

One set of results showed that boys were rated as being less engaged than girls. The boys were also rated as being less happy and relaxed than the girls. Probably the more important finding was that these gender differences in child behavior were completely statistically accounted for by the differential parent-child relationships observed. Those boys who had the same relationship with their mothers as the girls tended to be just as engaged, happy, and relaxed as the girls. Thus, as other studies suggest (Mandara et al., 2010; Tamis-LeMonda et al., 2009), it may be that girls are better behaved and more engaged in various activities than boys because they receive more nurturing parenting than boys.

These results should be interpreted in light of the study's limitations. The primary limitations are the correlational and cross-sectional nature of the study. Although up to four trained observers 
rated each interaction, one cannot say definitively that maternal parenting behavior caused child behavior directly. Undoubtedly the larger social context of African American boys' development is somewhat different than that of girls, and this may have consequences for their behavior over and above the parenting they receive. Mothers will also likely respond to their child's behavior to some degree (Pettit et al., 2001). Thus, another plausible explanation is that boys were less engaged in the task than girls simply because of the task, and mothers' behaviors were a response to boys' lack of interest. Randomized studies that train parents to behave in specific ways during the interactions would be very useful for estimating the direct causal effects of parenting on subsequent child behavior. Future research should also vary the task.

The validity of observational methods in general may be a question. Although this study included male and female raters of various ethnic backgrounds who were blind to the purpose of the study and the interrater reliabilities were very high, social stereotypes about African American male and female behavior could possibly influence the results. The fact that these results coincide with self-report survey studies gives us more confidence in the validity of the results, but it does not eliminate the concerns. The generalizability of the findings may also be a question, as it is a relatively small sample and all of the participants lived in southern California. It is possible that different social experiences will lead African Americans in other parts of the country to have less gendered parent-child relationships. Furthermore, only one child per mother participated in the study. The gender differences in parent-child relations may be less or even greater when parents simultaneously interact with multiple children. Future studies should also examine within-family gender differences. The fact that only mothers were used in the current study is related to the larger problem of the severely limited research on the parenting of African American fathers. Therefore, future studies should use larger and more geographically diverse samples of African American families and observe the interactions between different configurations of family members.

\section{Implications for Practice}

Despite these limitations, there are a number of implications for future research and practice that can be tentatively drawn from this study. Although this was obviously not a randomized experiment, the overall pattern of results is consistent with most prevailing notions of parenting and suggests that being emotionally responsive and allowing youth a sufficient amount of autonomy, coupled with high expectations for engagement, makes them more motivated and engaged in the task. It is also evident from these results and the few prior studies in this area that African American mothers, like European American mothers, have different parent-child relationships with their sons and daughters. This pattern seems to be consistent among mother-child relationships throughout much of the world (Barrett Singer \& Weinstein, 2000; Brody et al., 1992; Lytton \& Romney, 1991; Mandara et al., 2010). Very similar results have also been found for father-child relationships. Fathers tend to be more demanding of their sons than their daughters (Conrade \& Ho, 2001; Wilson, 1986). Thus, differential mother-child and father-child relationships may not necessarily be problematic for most children.

African American children, however, are reared in a relatively unique social situation. Compared to the average mother in the United States, the average African American mother has to handle a great deal more of the childrearing responsibilities on her own because they are more likely to be single than any other group of mothers in the United States (Kreider \& Elliott, 2009). Furthermore, the common notion that most modern African American children are raised in a communal African-like village with an abundance of grandparents, aunts, and uncles sharing in the childrearing responsibilities is simply not true. Although that may have been true for prior generations, the average African American child today is raised with his or her mother and siblings, especially as they get older (Kreider \& Elliott, 2009). Given that parents in general have to be judicious about how they spend their time and energy (Hertwig, Davis, \& Sulloway, 2002), this may force many African American mothers to subconsciously focus more of their energy on the child with the greater perceived potential to succeed in society. This may then explain why the gender differences in mother-child relationships are especially large among African Americans.

Most importantly, these results suggest that the less optimal parent-child relationships experienced by African American boys facilitates 
the disparity in behavior problems and achievement between them and African American girls. One clear implication of these findings for practice is that ameliorating the gender differences in parent-child relationships will significantly reduce the gender disparities in various outcomes. Thus, the primary intervention efforts should be to train parents to avoid this likely subconscious tendency to differentially socialize their sons and daughters. More specifically, empirically informed and culturally sensitive interventions that train parents how to be warm and loving as well as how to encourage both male and female children to excel and be actively engaged in productive endeavors may help to reduce gender disparities in a variety of outcomes.

\section{NoTE}

This research was supported by a grant from the National Institute of Child Health and Human Development (1R01HD030614) to Carolyn B. Murray.

\section{REFERENCES}

Arbuckle, J. L. (2007). Amos 16.0 user's guide. Spring House, PA: Amos Development Corp.

Aspland, H., \& Gardner, F. (2003). Observational measures of parent-child interaction: An introductory review. Child and Adolescent Mental Health, 8, 136-143. doi:10.1111/1475-3588.00061

Barrett Singer, A. T., \& Weinstein, R. S. (2000). Differential parental treatment predicts achievement and self-perceptions in two cultural contexts. Journal of Family Psychology, 14, 491-509. doi:10.1037//0893-3200.14.3.491

Baumrind, D. (2005). Patterns of parental authority and adolescent autonomy. New Directions for Child and Adolescent Development, 108, 61-69. doi:10.1002/cd.128

Bean, R. A., Barber, B. K., \& Crane, D. R. (2006). Parental support, behavioral control, and psychological control among African American youth: The relationships to academic grades, delinquency, and depression. Journal of Family Issues, 27, 1335 - 1355. doi: $10.1177 / 0192513$ X06289649

Brody, G. H., Stoneman, Z., \& McCoy, J. K. (1992). Parental differential treatment of siblings and sibling differences in negative emotionality. Journal of Marriage and the Family, 54, 643-651. doi:10.2307/353250

Chun, H., \& Mobley, M. (2010). Gender and gradelevel comparisons in the structure of problem behaviors among adolescents. Journal of Adolescence, 33, 197-207. doi:10.1016/j.adolescence. 2009.03.010
Conrade, G., \& Ho, R. (2001). Differential parenting styles for fathers and mothers: Differential treatment for sons and daughters. Australian Journal of Psychology, 53, 29-35. doi:10.1080/00049530108255119

Dunn, J., Stocker, C., \& Plomin, R. (1990). Nonshared experiences within the family: Correlates of behavioral problems in middle childhood. Development and Psychopathology, 2, 113-126. doi:10.1017/S0954579400000651

Eyberg, S. M., McDiarmid, M., Duke, M., \& Boggs, S. R. (2004). Manual for the Dyadic Parent-Child Interaction Coding System (3rd ed.). Retrieved from http://pcit.phhp.ufl.edu/DPICS files/DPICS\%20Draft\%203.03.pdf

Glauber, R. (2008). Race and gender in families and at work: The fatherhood wage premium. Gender \& Society, 22, 8-30.

Gupta, S. (2006). The consequences of maternal employment during men's childhood for their adult housework performance. Gender \& Society, 20, $60-86$.

Harris, A. C. (1996). African-American and AngloAmerican gender identities: An empirical study. Journal of Black Psychology, 22, 182-194. doi:10.1177/00957984960222004

Hertwig, R., Davis, J. N., \& Sulloway, F. J. (2002). Parental investment: How an equity motive can produce inequality. Psychological Bulletin, 12, 728-745. doi:10.1037//0033-2909.128.5.728

Hill, S. A (2002). Teaching and doing gender. Sex Roles, 47, 493-504. doi:10.1023/A:1022026 303937

Hill, S. A., \& Zimmerman, M. K. (1995). Valiant girls and vulnerable boys: The impact of gender and race on mothers' caregiving for chronically ill children. Journal of Marriage and the Family, 57, 43-53. doi: $10.2307 / 353815$

Kreider, R. M., \& Elliot, D. B. (2009). America's families and living arrangements: 2007. Washington, DC: Current Population Reports, U.S. Census Bureau.

Landry, B. (2000). Black working wives: Pioneers of the American family revolution. Berkeley, CA: University of California Press.

Landry, S. H., Smith, K. E., \& Swank, P. R. (2006). Responsive parenting: Establishing early foundations for social, communication, and independent problem-solving skills. Developmental Psychology, 42, 627-642. doi:10.1037/a0013030

Lytton, H., \& Romney, D. M. (1991). Parents' differential socialization of boys and girls: A metaanalysis. Psychological Bulletin, 109, 267-296. doi:10.1037//0033-2909.109.2.267

Mandara, J. (2008). Parent-child relations. In W. A. Darity (Ed.), International encyclopedia of the social sciences (2nd ed.). Farmington Hills, MI: Macmillan Reference. 
Mandara, J., \& Pikes, C. L. (2008). Guilt trips and love withdrawal: Does mothers' use of psychological control predict depressive symptoms among African American adolescents? Family Relations, 57, 602-612. doi:10.1111/j. 1741-3729.2008.00526.x

Mandara, J., Varner, F., \& Richman, S. (2010). Do African American mothers really "love" their sons and "raise" their daughters? Journal of Family Psychology, 24, 41-50. doi:10.1037/a0018072

McHale, S. M., Updergraff, K. A., Jackson-Newsom, J., Tucker, C. J., \& Crouter, A. C. (2000). When does parents' differential treatment have negative implications for siblings? Social Development, 9, 149-172. doi:10.1111/1467-9507.00117

McKee, L., Roland, R., Coffelt, N., Olson, A. L., Forehand, R., Massari, C., Jones, D., Gaffney, C. A., \& Zens, M. S. (2007). Harsh discipline and child behavior problems: The roles of positive parenting and gender. Journal of Family Violence, 22, 187-196. doi:10.1007/s10896-007-9070-6

Miller, S., Malone, P. S., \& Dodge, K. A. (2010). Developmental trajectories of boys' and girls' delinquency: Sex differences and links to later adolescent outcomes. Journal of Abnormal Child Psychology, 38, 1021 - 1032. doi:10.1007/s10802010-9430-1

Morsbach, S. K., \& Prinz, R. J. (2006). Understanding and improving the validity of self-report of parenting. Clinical Child and Family Psychology Review, 9, 1-21. doi:10.1007/s10567-006-0001-5

Patterson, G. R., \& Forgatch, M. S. (1995). Predicting future clinical adjustment from treatment outcome and process variables. Psychological Assessment, 7, 275-285. doi:10.1037//1040-3590.7.3.275

Peacock, M. J., Murray, C. B., Ozer, D., \& Stokes, J. (1996). The development of the Black Family Process Q-sort. In R. Jones (Ed.), Handbook of tests and measurements for Black populations (Vol. 4, pp. 475-493). Hampton, VA: Cobb \& Henry.

Pettit, G. S., Laird, R. D., Dodge, K. A., Bates, J. E., \& Criss, M. M. (2001). Antecedents and behaviorproblem outcomes of parental monitoring and psychological control in early adolescence. Child Development, 72, 583-598. doi:10.1111/14678624.00298

Preacher, K. J., \& Hayes, A. F. (2004). SPSS and SAS procedures for estimating indirect effects in simple mediation models. Behavior Research Methods Instruments and Computers, 36, 717-731. doi:10.3758/BF03206553

Sagrestano, L. M., McCormick, S. H., Paikoff, R. L., \& Holmbeck, G. N. (1999). Pubertal development and parent-child conflict in low-income, urban, African American adolescents. Journal of Research on Adolescence, 9, 85-107. doi:10.1207/s15327795jra0901_5
Sessa, F. M., Avenevoli, S., Steinberg, L., \& Morris, A. S. (2001). Correspondence among informants on parenting: Preschool children, mothers, and observers. Journal of Family Psychology, 15, 53-68. doi:10.1037//0893-3200.15.1.53

Shanahan, L., McHale, S. M., Crouter, A. C., \& Osgood, D. W. (2007). Warmth with mothers and fathers from middle childhood to late adolescence: Within- and between-families comparisons. Developmental Psychology, 43, 551-563. doi:10.1037/0012-1649.43.3.551

Shanahan, L., McHale, S. M., Crouter, A. C., \& Osgood, D. W. (2008). Linkages between parents' differential treatment, youth depressive symptoms, and sibling relationships. Journal of Marriage and Family, 70, 480-494. doi:10.1111/j. 1741-3737.2008.00495.x

Sirin, S. R., \& Rogers-Sirin, L. (2005). Components of school engagement among African American adolescents. Applied Developmental Science, 9, 5-13.doi:10.1207/s1532480xads0901_2

Skiba, R. J., Michael, R. S., Nardo, A. C., \& Peterson, R. L. (2002). The color of discipline: Sources of racial and gender disproportionality in school punishment. Urban Review, 34, 317-342. doi:10.1023/A:1021320817372

Smetana, J. G. (2000). Middle-class African American adolescents' and parents' conceptions of parental authority and parenting practices: A longitudinal investigation. Child Development, 71, 1672 - 1686. doi:10.1111/1467-8624.00257

Smetana, J., \& Gaines, C. (1999). Adolescentparent conflict in middle-class African American families. Child Development, 70, 1447-1463. doi:10.1111/1467-8624.00105

Stephenson, M. T., \& Holbert, R. L. (2003). A Monte Carlo simulation of observable versus latent variable structural equation modeling techniques. Communication Research, 30, 332-354. doi:10.1177/0093650203030003004

Tamis-Lemonda, C. S., Briggs, R. D., McClowry, S. G., \& Snow, D. L. (2009). Maternal control and sensitivity, child gender, and maternal education in relation to children's behavioral outcomes in African American families. Journal of Applied Developmental Psychology, 30, 321 - 331 . doi:10.1016/j.appdev.2008.12.018

Tucker, C. J., McHale, S. M., \& Crouter, A. C. (2003). Dimensions of mothers' and fathers' differential treatment of siblings: Links with adolescents' sextyped personal qualities. Family Relations, 52, 82 - 89. doi:10.1111/j.1741-3729.2003.00082.x

U.S. Bureau of the Census. (1996). Current population reports, P23-192, subject index to current population reports and other population report series. Washington, DC: U.S. Government Printing Office.

Williams, J. H., Van Dorn, R. A., Ayers, C. D., Bright, C. L., Abbott, R. D., \& Hawkins, J. D. 
(2007). Understanding race and gender differences in delinquent acts and alcohol and marijuana use: A developmental analysis of initiation. Social Work Research, 31, 71-81.

Wilson, M. N. (1986). Perceived parental activity of mothers, fathers, and grandmothers in threegenerational Black families. Journal of Black
Psychology, 12, 43 -59. doi:10.1177/009579848601 200201

Winsler, A., \& Wallace, G. L. (2002). Behavior problems and social skills in preschool children: Parentteacher agreement and relations with classroom observations. Early Education \& Development, 13, 41 - 58. doi:10.1207/s15566935eed1301_3 